\title{
About empirical models predicting the missile perforation of concrete barriers
}

\author{
J. Baroth, L. Daudeville, Y. Malécot \\ Université Joseph Fourier - Grenoble 1 / Grenoble INP / CNRS \\ 3SR Lab, Grenoble, F 38041, France \\ jbaroth@ujf-grenoble.fr
}

\begin{abstract}
This paper deals with empirical formulae predicting the perforation of reinforced concrete barriers. These formulae are usually validated for hard impacts only. Consequently, on the one hand, a simple method is proposed in case of soft impacts. For various tests, experimental and model predictions of perforation show a good agreement. On the other hand, recent tests at the material scale show that the behaviour of concrete under high confinement does not depend on the unconfined compressive strength of concrete after 28 days, $f_{c 28}$. Therefore analytical models based on $f_{c 28}$ need to be considered with caution.

RÉSUMÉ. Cet article se focalise sur les modèles analytiques de prévision de la perforation de voiles en béton armé sous impact. Ces modèles ne sont en général valables que pour des projectiles rigides. D'une part, une méthode simple de prévision de la perforation est alors proposée dans le cas d'impacts mous. Les formules qui en découlent permettent de prévoir la perforation de dalles impactées dans le cadre de plusieurs campagnes de tests. D'autre part, de récents tests à l'échelle du matériau montrent que le comportement du béton sous fort confinement ne dépend pas de la résistance en compression simple à 28 jours, $f_{c 28}$. Par conséquent, les modèles analytiques pour lesquels le béton est complètement caractérisé par $f_{c 28}$ doivent être utilisés avec précaution.

KEY-WORDS: soft and hard impacts, reinforced concrete, perforation

MOTS-CLES: impacts durs et mous, béton armé, perforation
\end{abstract}




\section{Introduction}

Different approaches exist to assess the possible perforation of a barrier submitted to a missile impact: experimental, numerical and particularly empirical methods are used depending on materials and stiffness of both target and striker. (Eibl 1987) has defined soft and hard impacts. Li et al. (2005) and Buzaud et al (2007) have presented and assessed the existing empirical formulae used for the perforation prediction of reinforced concrete (RC) targets in case of hard impacts, i.e. rigid projectiles compared to the concrete target. Mebarki et al. (2008) have carried out a similar study for steel targets.

Empirical formulae used for the design of reinforced concrete barriers submitted to missile impacts consist of ballistic limits in the case of hard impacts. Only one empirical formula found suits for soft impacts (CEB, 1988), i.e. rigid targets compared to the projectiles, under some conditions. Generally, the prediction of perforation in case of soft impacts is based upon the assumption that the deformation of the projectile is independent on the structural response of the target. This assumption allows evaluating the contact force due to the projectile (Riera 1968).

In a first section, this article presents empirical formulae for the perforation prediction of reinforced concrete targets under impacts, the range of variables over which the formulae were identified is given. In a second section, the balance of energy in case of soft impacts is examined. It allows, under some assumptions, the prediction of the ballistic limit (or limit velocity). In a third section, the relevance of the various presented models is evaluated on the basis of tests of soft impacts performed at Meppen in the 70's (Jonas et al., 1979), (Nachtsheim et al., 1982) and recently performed (Iris 2010), (Pontiroli et al., 2011). The fourth section presents recent results showing that the unconfined compressive strength of concrete cylinders after 28 days of ageing, $f_{c 28}$, should not be considered as the only material parameter characterizing the perforation resistance of concrete barriers submitted to impacts. Therefore, empirical formulae generally used for the design of impacted concrete structures must be used with caution.

\section{Perforation prediction of reinforced concrete barriers}

Only one analytical approach has been found in literature dealing with the prediction of concrete barriers under soft impacts (CEB 1988). This method is derived from load-time measurements of a $20000 \mathrm{~kg}$ military aircraft impacting a reinforced concrete wall; it predicts perforation when the average dynamic load, applied by the missile, reaches the dynamic punching strength of the slab. From this study, the ballistic limit of cylindrical deformable projectiles, of mass $M(\mathrm{~kg})$, diameter $d(\mathrm{~m})$, impacting RC structures is deduced: 


$$
V_{C E B}=50 \frac{\left(r_{d} f_{c, \text { cube }}\right)^{1 / 6}}{M^{0.31}} \sqrt{T(3.14 d+7.85 T)}
$$

Where $r_{d}(\%)$ is the percentage of reinforcement, $T(\mathrm{~m})$ is the distance between the impact face and the rebar mesh ( $T \approx$ thickness of the target). $f_{c, \text { cube }}$ is the characteristic compressive strength of concrete cubes after 28 days of ageing $\left(f_{c, \text { cube }} \approx 1.25 f_{c 28}\right)$.

Authors estimated this prediction with about $20 \%$ precision, if following ranges of variables are satisfied, denoting $A g$ the aggregate size: $0.07<T<0.9 \mathrm{~m}$; $0.66<d / T<1.3 ; 25<f_{c, \text { cube }}<63 \mathrm{MPa} ; 0.05<A g / T<0.07 ; 0.22<r_{d}<1.26 \%$.

Concerning hard impacts, among various formulae predicting perforation - see the state of the art (Li et al., 2005) - Buzaud et al. (2007) have selected 8 formulae estimating the ballistic limit of cylindrical rigid projectiles, of mass $M$ diameter $d$, impacting RC structures of thickness $e$. They propose to assess these formulae using a database of 151 tests. According to this analysis, the following formula [2] is well satisfied if its validity domain is a priori respected (Berriaud 1978).

$$
V_{1}=1.3 \rho_{c}^{1 / 6} f_{c 28}^{0.5}\left(\frac{d e^{2}}{M}\right)^{2 / 3}
$$

Formula [2] is supposed valid (with $10 \%$ precision) for the following range of variables : $0.5<d / e<1.5 ; 20<V<250 \mathrm{~m} / \mathrm{s} ; 30<f_{c 28}<45 \mathrm{MPa} ; 150<M_{a}<250$ $\mathrm{kg} / \mathrm{m}^{3} ; 0.5<r_{d}<0.8 \% ; 0,5<M / \rho_{c} e^{2}<1,5 ; 30<M<300 \mathrm{~kg} ; 10<d<30 \mathrm{~cm}$; $10<e<60 \mathrm{~cm}$, where $M_{a}$ is the reinforcement density, $\rho_{c}$ is the mass density.

Formula [2] was used for the design of the containment wall of French nuclear reactors. It was improved in order to extend its validity range, in particular concerning concrete strength, the reinforcement ratio and the projectile nose shape (Berriaud et al., 1983):

$$
V_{2}^{2}=1,89 f_{c 28} \rho_{c}^{1 / 3}\left(\frac{d e_{p}^{2}}{M}\right)^{4 / 3}\left(\frac{f_{c 28}}{\sigma_{0}}\right)^{-1 / 2} N^{2}\left(0,35\left(\frac{M_{a}}{M_{a 0}}\right)^{\gamma}+0,65\right)^{2}
$$

with $\sigma_{0}=36 \mathrm{MPa}, M_{a 0}=200 \mathrm{~kg} / \mathrm{m}^{3}, N=1$ and $N=1.18$ for noses respectively flat, hemispheric then conic with angle $\alpha$ :

$$
N=3,24-6,01 \cdot 10^{-2} \alpha+6,58.10^{-4} \alpha^{2}-3,34 \cdot 10^{-6} \alpha^{3}-6,45 \cdot 10^{-9} \alpha^{4}
$$

The validity domain of [3] is a priori: $0.25<d / e<3.3 ; 20<V<250 \mathrm{~m} / \mathrm{s}$; $15<f_{c 28}<80 \mathrm{MPa} ; 0<M_{a}<300 \mathrm{~kg} / \mathrm{m}^{3}$. 
Buzaud et al. (2007) concluded that formula [3] is the most precise among 8 formulae when they are applied to 151 tests including some of them out of their validity domain. We point out the high sensitivity of the ballistic limit regarding variations of the nose shape. The only material parameter characterizing concrete strength in [1]-[4] is $f_{c 28}$, the unconfined compressive strength after 28 days of ageing. According to design codes, the calculation of concrete structures is usually based on $f_{c 28}$, based on empirical relations, the majority of other characteristics can be deduced from $f_{c 28}$ (tensile strength $f_{t}$, Young's modulus $E$, etc.). Lots of concrete $3 \mathrm{D}$ constitutive models also use $f_{c 28}$ to scale the concrete $3 \mathrm{D}$ strength criterion. The section 4 examines the pertinence of using this unique parameter for characterizing concrete resistance to perforation.

Moreover, most formulae predicting perforation are not suited in case of soft impacts. In such cases, only numerical approaches (finite or discrete element methods) or non explicit analytical formulae seem available. The aim of the following section is to propose and to valid an explicit analytical formulation, to estimate ballistic limits. The difficulty is then to take into account the projectile deformation during the crash.

\section{Prediction of concrete target perforation under soft impact}

An explicit formulation is proposed. Then it is applied to results from various soft impact tests performed at Meppen in the 70's (Jonas et al., 1979), (Nachtsheim et al. 1982) and recently performed (Iris, 2010), (Pontiroli et al., 2011).

\subsection{Analytical formulation of ballistic limits}

\subsubsection{Energetic formulation of the impact}

Let us consider the energy $W_{p}$ dissipated by the crushing of the projectile, as the mechanical work done by the constant crushing force $F_{p}$ through the crushed length $u$ of the projectile writes $W_{p}=F_{p} u$. That is equivalent to average the crushing force exerted by the projectile on the target during the crash. The idea of averaging this force was also found in (CEB 1988).

Let us denote $\Sigma=\frac{1}{2} M\left(V_{0}\right)^{2}$ the total kinetic energy at impact, where $V_{0}$ is the ballistic limit of the soft projectile. Let us suppose that this energy writes

$$
\Sigma=W_{p}+\Sigma_{p}+W_{c}+\Sigma_{c}
$$

The ballistic limit of the projectile, once it has been deformed, is denoted $V<V_{0}$, such that the kinetic energy of the projectile becomes $\Sigma_{p}=\frac{1}{2} M V^{2}$. The motion of 
the target is characterized by the mechanical work $W_{c}=M_{s} a_{s} u_{s}$ and the kinetic energy $\Sigma_{c}=\frac{1}{2} M_{s} V_{s}^{2}$. If the motion of the target is supposed insignificant, a simple estimation of the ballistic limit $V$ can be deduced from [5]:

$$
V=\sqrt{V_{0}^{2}+\frac{2 F_{p} u}{M}}
$$

\subsubsection{Estimation of the crushing force of the projectile}

The crushing force for hollow missiles is estimated by the following formula, based on Rankine's equation (Bignon et al., 1980).

$$
F_{p}=2 \pi e\left(\frac{\sqrt{2\left(1-v^{2}\right)}}{e E}+\frac{2}{d f_{y}}\right)^{-1}
$$

where $E$ is the Young's modulus $(\mathrm{Pa}), v$ is the Poisson ratio, $d$ is the projectile diameter $(\mathrm{m}), f_{y}$ is its limit strength $(\mathrm{Pa}), e$ is the thickness of the target $(\mathrm{m})$.

In order to take into account the increase of the strength with the strain rate, the dynamic limit strength $f_{y}^{s}$ is usually estimated, instead of $f_{y}$. Nevertheless, that is questionable in this work. Indeed, this effect of strain rate is maximal at the impact but decreases during the crash; therefore taking into account this effect and the proposed formulation should lead to overestimate crushing strengths and then ballistic limits. Moreover, the estimation of $f_{y}^{s}$ does not seem precise. Applying the Johnson-Cook law (Johnson et al., 1985) to a common steel ( $f_{y}=235 \mathrm{MPa}$ ), Pontiroli et al., (2011) predict a dynamic limit strength $f_{y}^{s}$ greater than $480 \mathrm{MPa}$, whereas a method from (Jones 1989), used in (Moore et al., 2011), leads to a value in the order of $460 \mathrm{MPa}$. The relevance of taking into account the strain rate effect in this work will be discussed in the following.

\subsection{Application to soft impacts}

Selected formulae predicting the perforation are applied to various tests, taking into account the crushing and the effect of the strain rate. These estimations are compared to test results. For all tests, projectiles are hollow metallic cylinders (soft steel, Poisson ratio $v=0.3$, mass density $\rho_{p}=7850 \mathrm{~kg} / \mathrm{m}^{3}$, Young's $E=210 \mathrm{GPa}$ ).

\subsubsection{MEPPEN tests}

Projectiles are steel cylinders $\left(d=60 \mathrm{~cm}, f_{y}=235 \mathrm{MPa}\right)$, whose lowest thickness is $7 \mathrm{~mm}$ over a length of $2.5 \mathrm{~m}$ and $10 \mathrm{~mm}$ over a length of $3 \mathrm{~m}$. These parts can be crushed on a $6.5 \times 6 \mathrm{~m}^{2}$ slab of thickness $70 \mathrm{~cm}$. The concrete slab is characterized 
by a compressive strength $f_{c}$ of $37.1 \mathrm{MPa}$ and a density $\rho_{c}$ of $2260 \mathrm{~kg} / \mathrm{m}^{3}$ (Jonas et al., 1979). Others characteristics of these tests are in table 1.

\begin{tabular}{|c|c|c|c|c|c|}
\hline \multicolumn{3}{|c|}{ Reference / damage } & $\begin{array}{l}\text { II-2 / no } \\
\text { perforation }\end{array}$ & $\begin{array}{c}\text { II-5 / } \\
\text { perforation } \\
\text { limit }\end{array}$ & $\begin{array}{c}\text { II-9 / } \\
\text { perforation }\end{array}$ \\
\hline \multirow[b]{2}{*}{ Tests } & \multicolumn{2}{|c|}{ Mass $M$} & $1016 \mathrm{~kg}$ & $974 \mathrm{~kg}$ & $970 \mathrm{~kg}$ \\
\hline & \multicolumn{2}{|c|}{ Impact velocity $V$} & $\begin{array}{c}172.2 \mathrm{~m} / \mathrm{s} \\
<V_{0}\end{array}$ & $\begin{array}{c}234.8 \mathrm{~m} / \mathrm{s} \\
\# V_{0}\end{array}$ & $\begin{array}{c}235.8 \mathrm{~m} / \mathrm{s} \\
>V_{0}\end{array}$ \\
\hline \multirow{5}{*}{$\begin{array}{c}\text { Soft } \\
\text { impact } \\
\text { models }\end{array}$} & \multicolumn{2}{|c|}{ [1] } & $231 \mathrm{~m} / \mathrm{s}$ & $232 \mathrm{~m} / \mathrm{s}$ & $232 \mathrm{~m} / \mathrm{s}$ \\
\hline & \multirow{2}{*}{$\begin{array}{l}\text { no strain } \\
\text { rate effect }\end{array}$} & [6] $7 \mathrm{~mm}$ & $170 \mathrm{~m} / \mathrm{s}$ & $173 \mathrm{~m} / \mathrm{s}$ & $172 \mathrm{~m} / \mathrm{s}$ \\
\hline & & [6] 7+10 $\mathrm{mm}$ & $246 \mathrm{~m} / \mathrm{s}$ & $250 \mathrm{~m} / \mathrm{s}$ & $250 \mathrm{~m} / \mathrm{s}$ \\
\hline & \multirow{2}{*}{$\begin{array}{c}\text { strain rate } \\
\text { effect }\end{array}$} & [6] $7 \mathrm{~mm}$ & $214 \mathrm{~m} / \mathrm{s}$ & $217 \mathrm{~m} / \mathrm{s}$ & $217 \mathrm{~m} / \mathrm{s}$ \\
\hline & & [6] 7+10 mm & $326 \mathrm{~m} / \mathrm{s}$ & $333 \mathrm{~m} / \mathrm{s}$ & $334 \mathrm{~m} / \mathrm{s}$ \\
\hline $\begin{array}{c}\text { Hard } \\
\text { impact }\end{array}$ & \multicolumn{2}{|c|}{ Models [2-3] } & $121 \mathrm{~m} / \mathrm{s}$ & $122 \mathrm{~m} / \mathrm{s}$ & $121 \mathrm{~m} / \mathrm{s}$ \\
\hline
\end{tabular}

Table 1. Data concerning Meppen tests (Jonas et al., 1979) ; measured initial velocities and estimated ballistic limits $(\mathrm{m} / \mathrm{s})$ (hard and soft impacts)

Table 1 presents velocities $(\mathrm{m} / \mathrm{s})$ measured and estimated for Meppen tests. For each test, the level of damage, the measured impact velocity and estimated ballistic limits are given. These limits are estimated regarding both hard and soft impacts.

In case of hard impact, formulae [2-3] approximate a ballistic limit of $121 \mathrm{~m} / \mathrm{s}$, with a relative difference less than $1 \%$. Therefore only the simplest formula [2] is used in the following. Table 1 shows that formulae [2-3] are not suited in case of these soft impacts, an initial velocity of $172 \mathrm{~m} / \mathrm{s}$ being not enough to perforate.

In case of soft impact, table 1 provides five estimations. First, the formula [1] from [CEB 1988] is applied, its validity domain being verified. For the 3 tests, $232 \mathrm{~m} / \mathrm{s}$ is a particularly good estimation of the ballistic limit. However, [CEB 1988] does not precise if Meppen tests results have been used to calibrate their approach. Then soft impacts are studied considering that lower and upper values of the dissipated energy during the crushing of the projectile are respectively given by $W_{p l}=2.5 F_{p}$ and $W_{p 2}=W_{p l}+3 F_{p}$, where $F_{p}, F_{p}$, are the crushing forces given by [7], regarding respectively the $7 \mathrm{~mm}$ thick and the $10 \mathrm{~mm}$ thick parts of the projectile. These two parts are studied in table 1, which presents estimated ballistic limits, using formula [6] based on [2]. These velocities are also estimated taking into account the effect of strain rate (in italics), using the dynamic limit strength $f_{y}^{s}$ instead of $f_{y}$ in [7].

Obviously, [6] provides relevant estimations of lower and upper values of the ballistic limit, taking into account that all the first deformable ( $7 \mathrm{~mm}$ thick) part has been crushed but not all the other deformable (10 mm thick) part. Taking into 
account the strain rate leads to higher estimations, in the same order, which seem logical but rather surestimated.

\subsubsection{IRIS tests}

Projectiles are metallic cylinders $\left(d=25.4 \mathrm{~cm}, f_{y}=340 \mathrm{MPa}, M=49,99 \mathrm{~kg}\right)$, whose lowest thickness is $3 \mathrm{~mm}$ over a length of $1 \mathrm{~m}$. These parts can be crushed on $15 \mathrm{~cm}$ thick slabs. Two tests are conducted with velocities equal to 110.15 and $111.56 \mathrm{~m} / \mathrm{s}$ [Moore et al., 2010]. The crushing force $F_{p}$ for this part is around $540 \mathrm{kN}$. Taking into account the effect of strain rate, this force is found around $630 \mathrm{kN}$ [Moore et al., 2010].

\begin{tabular}{|l|l|c|c|c|c|}
\hline $\begin{array}{l}\text { Tests / } \\
\text { damage }\end{array}$ & $\begin{array}{c}\text { impact } \\
\text { velocities } \\
\text { (tests) }\end{array}$ & $\begin{array}{c}\text { hard } \\
\text { impact } \\
{[2-3]}\end{array}$ & $\begin{array}{c}\text { soft } \\
\text { impact } \\
{[1]}\end{array}$ & $\begin{array}{c}\text { soft } \\
\text { impact } \\
{[6]}\end{array}$ & $\begin{array}{c}\text { soft impact } \\
\text { [6] with strain } \\
\text { effect }\end{array}$ \\
\hline $\begin{array}{c}1-2 / \mathrm{no} \\
\text { perforation }\end{array}$ & $\begin{array}{c}110.1-111.6 \\
\mathrm{~m} / \mathrm{s}\end{array}$ & 85 & 152 & 170 & 180 \\
$\mathrm{~m} / \mathrm{s}$ & $\mathrm{m} / \mathrm{s}$ & $\mathrm{m} / \mathrm{s}$ & $\mathrm{m} / \mathrm{s}$ \\
\hline
\end{tabular}

Table 2. Measured and estimated velocities, in case of Iris tests (no perforation)

Table 2 presents velocities $(\mathrm{m} / \mathrm{s})$ measured and estimated for Iris tests. The level of damage and measured impact velocity and estimated ballistic limits are given. These limits are deduced in case of hard and soft impacts.

In case of hard impact, formulae [2-3] approximate the ballistic limit, with a relative difference less than $1 \%$. Therefore only the simplest formula [2] is used. Table 2 shows that formulae [2-3] are not suited in case of these soft impacts: $111 \mathrm{~m} / \mathrm{s}$ are not enough to perforate, therefore $85 \mathrm{~m} / \mathrm{s}$ is a bad estimation.

In case of soft impact, table 2 provides three estimations. First, the formula [1] from [CEB 1988] is applied, its validity domain being verified. For the test II-4, $152 \mathrm{~m} / \mathrm{s}$ is not a bad estimation of the ballistic limit since $111 \mathrm{~m} / \mathrm{s}$ are not enough to perforate. Then soft impacts are studied considering that the dissipated energy during the crushing of the projectile is given by $W_{p}=1 F_{p}$ where $F_{p}$ is the crushing force given by [7]. Table 2 presents estimated ballistic limits, using formula [6] based on [2], taking into account the effect of strain rate (in italics) or not.

Obviously, [1, 6] provide better estimations of the ballistic limit than [2-3]. Taking into account the strain rate leads to a higher estimation, in the same order.

\subsubsection{VULCAIN tests}

Projectiles are metallic cylinders $\left(d=9,98 \mathrm{~cm}, f_{y}=235 \mathrm{MPa}\right)$, whose lowest thickness is $1 \mathrm{~mm}$ over a length of $25 \mathrm{~cm}$ and of $2 \mathrm{~mm}$ over a length of $30 \mathrm{~cm}$. These parts can potentially be crushed on $2.1 \times 2.1 \mathrm{~m}^{2}$ slabs of thickness $e(6$ and $7 \mathrm{~cm})$. 
Characteristics of tests are gathered in tables 3 and 4 (Pontiroli 2011). Tests 2 and 8 are presented in the last paper (Pontiroli et al., 2011).

\begin{tabular}{|c|c|c|}
\hline Parameters & Values & unit \\
\hline$\rho_{c}$ and $\rho_{p}$ & 2278 and 7850 & $\mathrm{~kg} / \mathrm{m}^{3}$ \\
\hline$r_{d}(e=6$ and $7 \mathrm{~cm})$ & 1 and 1.2 & $\%$ \\
\hline$f_{c}$ & 28.6 & $\mathrm{MPa}$ \\
\hline
\end{tabular}

Table 3. Common data to all tests (Pontiroli 2011)

\begin{tabular}{|c|c|c|c|c|c|c|c|c|c|}
\hline & 1 & 2 & 3 & 4 & 5 & 6 & 7 & 8 & 9 \\
\hline Reference & \#22 & \#24 & $\# 30$ & \#31 & \#35 & \#27 & \#43 & \#32 & \#34 \\
\hline$M(\mathrm{~kg})$ & 6.166 & 5.2073 & 5.0916 & 5.0728 & 5.0594 & 4.9853 & 5.0509 & 5.0653 & 5.0596 \\
\hline$e(\mathrm{~m})$ & 0.07 & 0.07 & 0.07 & 0.06 & 0.07 & 0.07 & 0.07 & 0.07 & 0.07 \\
\hline$V(\mathrm{~m} / \mathrm{s})$ & 135.5 & 107.5 & 92 & 89 & 73 & 93 & 80 & 70.2 & 68 \\
\hline
\end{tabular}

Table 4. Specific data concerning each of nine Vulcain tests (Pontiroli, 2011)

Figure 1 presents ratios between measured velocities at impact and estimated ballistic limits. Moreover, figure 1 shows levels of damage for the 9 slabs tested (Pontiroli 2010). In case of perforation (tests 1 to 4), ratios must be less than 1 . Instead, there is no perforation (ratio greater than 1). Test 6 is a particular case where all the concrete is perforated, but the projectile is just stopped by steel rods. Therefore the estimated ratio should be equal to one.

In case of hard impacts, formulae [2] and [3] are used. Figure 1 highlights insufficiency of classical formulae to distinguish perforation and no perforation. One notices for these tests that estimations [2] and [3] are quite different.

In case of soft impacts, three formulae are used.

First, formula [1] derived from CEB approach provides good estimations of perforation, excepted for tests 6 and 7. For these tests, there is no perforation and estimated ratios are respectively less than 1 and just equal to 1 . Secondly, formula [6] is used, considering respectively [2] and [3]. The crushing force is estimated, taking into account only the first deformable ( $1 \mathrm{~mm}$ thick) part of the projectile, as it is verified in tests (Pontiroli 2010). Results are rather satisfactory, particularly if formula [6] is based on [3]. For tests 3 and 4, formula [6] underestimates ballistic limits, as estimated ratios are just equal to one; they should have been lower, as there is clearly perforation. For test 6 , formula [6] provides a precise estimation of the ballistic limit, as the estimated ratio is just greater than one. For these tests, 
estimations do not take into account the effect of strain rate. In this case, formula [6] would have been unable to predict which slab is perforated.

This section has presented a formula complementary to the only one available [CEB 1988]. Both have been able to predict perforation for various test results of soft impacts. The purpose of the next section is to present experimental results which show limits of formulae used in case of impacts, where stresses in the target reach high values.

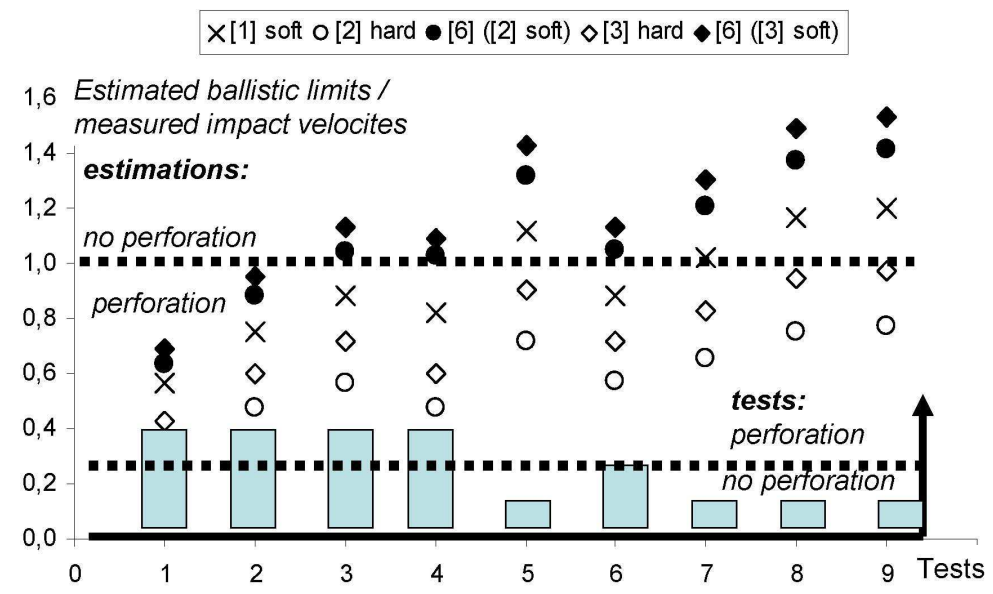

Erreur! Source du renvoi introuvable. Velocities measured and estimated (hard and soft impacts), $\mathrm{m} / \mathrm{s}$

\section{Constitutive behaviour of concrete under high triaxial stress state}

Gran and Frew (1997) have performed hard impact tests on concrete targets having an unconfined compressive strength of $43 \mathrm{MPa}$. The projectile was a $50 \mathrm{~mm}$ diameter steel sharp penetrator weighting $2.3 \mathrm{~kg}$ and was launched at $315 \mathrm{~m} / \mathrm{s}$. These authors have measured radial stresses at various depths and radii. They have shown that the maximum radial stress was about $400 \mathrm{MPa}$ and, according to analytical calculations, the mean stress was of the order of $1 \mathrm{Gpa}$. A priori, in case of soft impacts, mean stress should also reach high values.

In order to analyze the behaviour of concrete under stresses of the order of $1 \mathrm{Gpa}$, triaxial tests on plain concretes have been performed, using a large capacity triaxial press. Stress levels over passing one GigaPascal have been reached (Gabet et al., 2006, Gabet et al., 2008, Vu et al., 2009, Dupray et al., 2009, Poinard et al., 2010, Dupray et al., 2010, Malécot et al., 2010). In the following, complementary 
results aim to highlight that $f_{c 28}$ is a very poor indicator of the high-pressure mechanical response of concrete.

\subsection{Experimental set-up}

\subsubsection{Triaxial cell}

The tests have been conducted with a high-capacity triaxial press that allows loading a cylindrical concrete specimen $7 \mathrm{~cm}$ in diameter and $14 \mathrm{~cm}$ long. This press is able to generate a maximum confining pressure of $0.85 \mathrm{GPa}$ and an axial stress of 2.3 GPa. A displacement sensor located in the press is used to control the axial jack displacement, while a load sensor and pressure sensor placed inside the confinement cell display the stress state of the sample. The confining pressure and axial jack displacement are servo-controlled, which offers the possibility of creating several possible loading paths (Gabet et al., 2006, Gabet et al., 2008).

In the following, compressive stresses and contraction strains are assumed to be positive; $\sigma_{x}$ is the principal axial stress, $p$ the pressure inside the confining cell, $\sigma_{m}=$ $\left(\sigma_{x}+2 p\right) / 3$ the mean stress and $q=\sigma_{x}-p$ the principal stress difference (deviatoric stress). All tests have been conducted in following the same kind of loading path. The triaxial compression test begins with a hydrostatic test. Once the desired confinement has been reached, the specimen is then loaded axially while holding the confining pressure constant. Note that for most of the tests the maximum deviatoric stress reached value has not been imposed. It is a result of the test.

\subsubsection{Concrete samples: $f_{c 28}$ and $\mathrm{Sr}$}

In order to study the effect of $f_{c 28}$, from the composition of a reference ordinary concrete $\left(f_{c 28}=29 \mathrm{MPa}\right)$, two other concretes have been produced with $f_{c 28}$ equal to $21 \mathrm{MPa}$ and $57 \mathrm{MPa}$, respectively. These three concretes have different water/cement ratio $(W / C)$, but their aggregates skeletons are almost identical (see composition on table 5).

\begin{tabular}{|c|c|c|c|}
\hline Concrete composition and mechanical properties & C57 & $\mathrm{C} 29$ & $\mathrm{C} 21$ \\
\hline $0.5 / 8$ "D" gravel $\left(\mathrm{kg} / \mathrm{m}^{3}\right)$ & 1000 & 1008 & 991 \\
\hline $1,800 \mu \mathrm{m}$ "D" sand $\left(\mathrm{kg} / \mathrm{m}^{3}\right)$ & 832 & 838 & 824 \\
\hline CEM I 52.5 N PM ES CP2 cement (Vicat) $\left(\mathrm{kg} / \mathrm{m}^{3}\right)$ & 349 & 263 & 226 \\
\hline Water $\left(\mathrm{kg} / \mathrm{m}^{3}\right)$ & 136 & 169 & 181 \\
\hline Sikafluid Superplasticizer $\left(\mathrm{kg} / \mathrm{m}^{3}\right)$ & 4.5 & 0 & 0 \\
\hline$W / C$ ratio & 0.39 & 0.64 & 0.80 \\
\hline Density $\left(\mathrm{kg} / \mathrm{m}^{3}\right)$ & 2322 & 2278 & 2252 \\
\hline Average slump measured using the Abrams cone $(\mathrm{cm})$ & 7 & 6.9 & 14 \\
\hline Unconfined compression strength after 28 days $f_{c 28}(\mathrm{MPa})$ & 57 & 29 & 21 \\
\hline
\end{tabular}

Table 5. Compositions and mechanical properties of concretes C21, C29, C57. 
Besides, to evaluate the effect of the saturation ratio $S r$, tests have been conducted on dried, wet and saturated samples, for the C29 concrete. After some 4 months of conservation in water, the "dried" specimens are placed in a drying oven, at a temperature $T$ of $50^{\circ} \mathrm{C}$ and relative humidity $R H$ of $8 \%$, for a period lasting between 3 and 6 months. The saturation ratio of the "dried" concrete tested in this study is approximately $11 \%$. The "saturated" specimens are conserved in water between 6 and 10 months, after which they are wrapped in the multilayer membrane, just prior to the triaxial test. Lastly, the "wet" specimens are conserved in water and then a few days in the ambient laboratory atmosphere (a $T$ value near $18^{\circ} \mathrm{C}$ and $40 \%$ $R H$ ) during the instrumentation procedure ( $\mathrm{Vu}$ et al., 2009a).

Strain measurements are performed by use of an LVDT (Linear Variable Differential Transformer) axial sensor, along with one axial and two circumferential gauges. Given the porous nature of concrete, this high level of confinement has necessitated developing a multilayer protective membrane around the sample; this element is composed of $8 \mathrm{~mm}$ of latex and $2 \mathrm{~mm}$ of neoprene ( $\mathrm{Vu}$ et al., 2009b).

\subsection{Test results}

Figure 2 shows the results for the unconfined compression tests carried out on the four types of concrete samples. As it was expected, an increase in the Young's modulus $E$ and ultimate stress of the concrete $f_{c 28}$ can be observed with a decrease in Water/Cement ratio of the concrete mixture. Figure 2 also reveals that the saturation ratio of the sample has a very slight influence in unconfined compression compare to the water/cement ratio.

Figure 3 shows the hydrostatic part of triaxial tests conducted at a confining pressure of $650 \mathrm{MPa}$. This figure reveals that beyond $400 \mathrm{MPa}$ of confinement, the volumetric behaviour curves of dried concretes (C21, C29 or C57) run parallel, which suggests that the difference in incremental volumetric strains of these three concretes is significant only at low confinement levels. These phenomena are more obvious on Figure 4 which focuses on the hydrostatic behaviour of the same samples beyond a confining pressure of $400 \mathrm{MPa}$.

Figure 5 shows the deviatoric part of triaxial tests conducted at a confining pressure of $650 \mathrm{MPa}$. The results indicate that the deviatoric behaviour curves of dried concretes (C21, C29 or C57) practically overlap. The strength gap between these concretes is not anymore visible. The incremental behaviour of concretes becomes then independent from their unconfined compressive strength beyond a given confining pressure. On the contrary, the presence of free water in the sample seems to affect the volumetric stiffness only under high confinement. For a mean stress greater than around $200 \mathrm{MPa}$, the volumetric behavior of the wet concrete becomes stiffer than that of dried concrete (Figure 3). A relative difference of about $25 \%$ between the volumetric strains of dried and saturated samples at a mean stress of $650 \mathrm{MPa}$ can for example be noted. For these stress levels, the volumetric strains become significant compared to the initial air volume of the sample. The initially wet 
samples thus trend toward a degree of humidity close to saturation. The pore pressure developing within the material rises and exerts a significant influence on the measured stress. The presence of free water in the sample also reduces a lot the strength capacity (Figure 5). The resistance capacity of the dried samples is clearly higher. As such, no peak deviatoric stress is reached in the tests conducted on dried concrete at these high confinements. These results may be explained by the cohesion loss of the cementitious matrix, which provides the concrete with behaviour of the non-cohesive granular material type. The increase in dried concrete shear strength with confining pressure is thus explained by the friction existing between stacking grains. Limitation of the same strength observed for saturated concrete is probably due to pore pressure, which develops similarly to what is found in undrained soils.

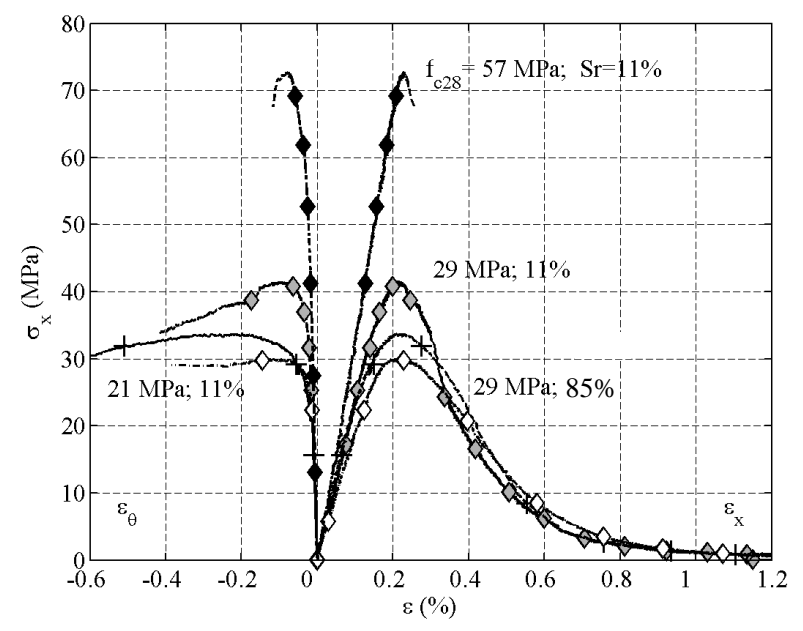

Figure 2. Axial stress $\sigma_{x}$ vs. strain components $\varepsilon_{x}$ and $\varepsilon_{\theta}$ for unconfined compression tests carried out on 4 types of 8 months aged concrete samples : $C 57 f_{c 28}=57 \mathrm{MPa}$ and $\mathrm{Sr}=11 \%(\diamond) ; C 29-11 \% f_{c 28}=29 \mathrm{MPa}$ and $\mathrm{Sr}=11 \%$ (grey diamond); $C 21$ $f_{c 28}=21 \mathrm{MPa}$ and $\mathrm{Sr}=11 \%(\diamond) ; C 29-85 \% f_{c 28}=29 \mathrm{MPa}$ and $\mathrm{Sr}=85 \%(+)$. 


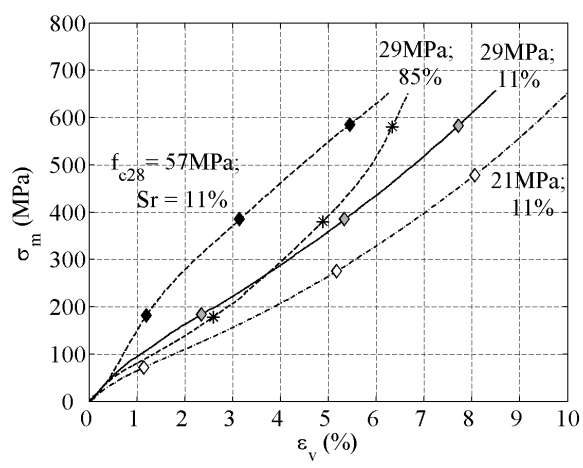

Figure 3. Mean stress $\sigma_{m} v s$. volumetric strain $\varepsilon_{v}$ for the hydrostatic part of triaxial tests (confining pressure of $650 \mathrm{MPa}$ ) on four types of concrete samples: C57 $f_{c 28}=57 \mathrm{MPa}$ and $\mathrm{Sr}=11 \%(\diamond) ; C 29-11 \% f_{c 28}=29 \mathrm{MPa}$ and $\mathrm{Sr}=11 \%$ (grey diamond); $C 21 f_{c 28}=21 \mathrm{MPa}$ and $\mathrm{Sr}=11 \%(\diamond) ; C 29-85 \% f_{c 28}=29 \mathrm{MPa}$ and $\mathrm{Sr}=85 \%$ (*).

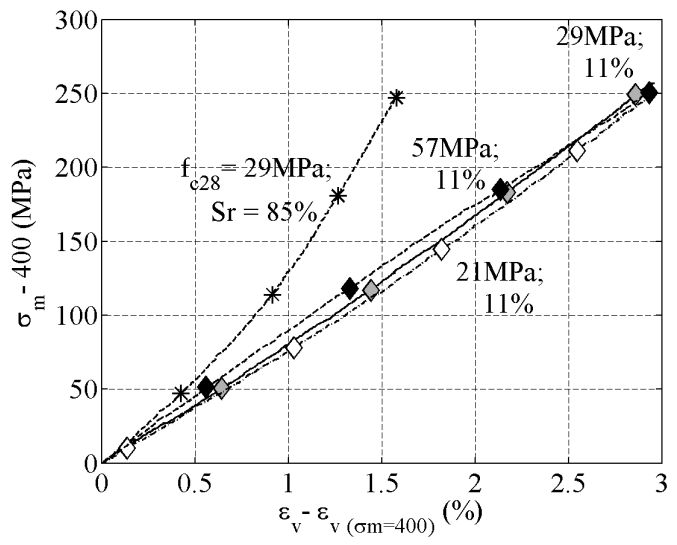

Figure 4. Mean stress $\sigma_{m}$ vs. volumetric strain variation above $400 \mathrm{MPa}$ $\Delta \varepsilon_{v}=\varepsilon_{v}-\varepsilon_{v 400 M P a}$ for the hydrostatic part of triaxial tests conducted at a confining pressure of $650 \mathrm{MPa}$ on four types of concrete samples: $C 57 f_{c 28}=57 \mathrm{MPa}$ and $\mathrm{Sr}=11 \%$ (४); $\quad \mathrm{C} 29-11 \% \quad f_{c 28}=29 \mathrm{MPa}$ and $\mathrm{Sr}=11 \%$ (grey diamond); C21 $f_{c 28}=21 \mathrm{MPa}$ and $\mathrm{Sr}=11 \%(\diamond) ; C 29-85 \% f_{c 28}=29 \mathrm{MPa}$ and $\mathrm{Sr}=85 \%$ (*). 
Figure 6 summarizes the strain limit state of concretes C21, C29 and C57, within the $\left(\sigma_{m} / f_{c 28}, q / f_{c 28}\right)$ deviatoric plane for all tests performed. It can be observed that beyond a mean stress of around $5 f_{c 28}$, the loading capacity of dried concrete strongly increases in a quasi-linear manner with respect to the mean stress whereas the ones of wet or saturated concretes almost remain constant. Figure 6 also shows, on the one hand, that at low mean stress level (below $5 f_{c 28}$ ) all the concretes are following the same curve whatever $S r$ or $f_{c 28}$ values are. On the other hand, beyond this critical mean stress (over $5 f_{c 28}$ ), one can observe that the limit states are very scattered depending on $\mathrm{Sr}$ or $f_{c 28}$ values. This last point shows that $f_{c 28}$ is poorly link to the loading capacity of concrete under high confinement.

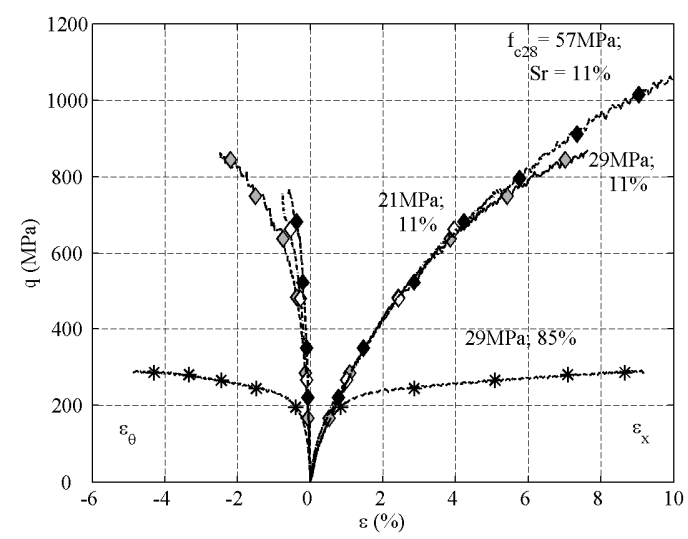

Figure 5. Stress deviator $q$ vs. strain components $\varepsilon_{x}$ and $\varepsilon_{\theta}$ for deviatoric part of triaxial tests conducted at a confining pressure of $650 \mathrm{MPa}$ on four types of concrete samples: $C 57 f_{c 28}=57 \mathrm{MPa}$ and $\mathrm{Sr}=11 \%(\diamond) ; C 29-11 \% f_{c 28}=29 \mathrm{MPa}$ and $\mathrm{Sr}=11 \% \quad$ (grey diamond); $\quad \mathrm{C} 21 \quad f_{c 28}=21 \quad \mathrm{MPa}$ and $\mathrm{Sr}=11 \% \quad(\diamond) ; \quad C 29-85 \%$ $f_{c 28}=29 \mathrm{MPa}$ and $\mathrm{Sr}=85 \%$ (*).

Figure 7 shows the relative limit state of concretes C21, C57, C29-70\%, C29$85 \%$ and $\mathrm{C} 29-100 \%$ to that of the reference concrete $\mathrm{C} 29-11 \%$ in the $\left(p, q / q_{C 29-11 \%}\right)$ plane. $q_{C 29-11 \%}$ is the limit deviator obtained for the reference concrete $\mathrm{C} 29-11 \%$ at an identical confining pressure. This presentation in terms of deviator relative to that of the reference concrete provides a better perception of the both the effect of the simple compressive strength at low confinement and the effect of the saturation ratio at high confinement. For low mean stress levels, the limit state of the concrete is heavily dependent on the cement matrix strength. This result was obviously the expected one. In contrast, the same figure also shows that this dependence of concrete limit state on $f_{c 28}$ decreases rapidly as mean stress rises. Beyond a critical confining pressure, the limit state curve actually becomes independent of $f_{c 28}$. 
Conversely, at a low level confining pressure, it is found that the limit states of the dried, wet and saturated samples all lie very close to one another (Figure 7). This result should come as no surprise since at such stress levels, concrete behaviour is governed by a still cohesive character. The presence of water in the sample does not exert therefore a very significant effect on the limit state. For higher confinement levels, the effect of water becomes predominant. The increase in peak deviatoric stress with respect to mean stress remains very low for the saturated samples. The shear strength of the dried concrete is then equal to 4 times the one of the saturated concrete for a confining pressure of $650 \mathrm{MPa}$, whereas their unconfined compressive strength is almost the same. Again, this phenomenon is likely explained by a pore pressure effect similar to that observed for an undrained granular material.

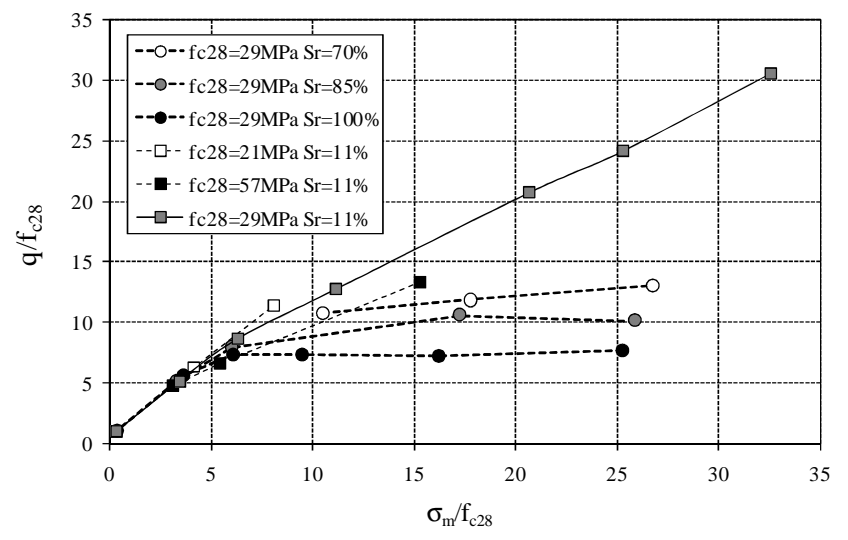

Figure 6. Limit states of concretes $C 21$ (Sr=11\%), C29 (Sr=11\%, 70\%, 85\% or $100 \%)$ and $C 57(S r=11 \%)$ : Deviatoric stress $q / f_{c 28} v s$. the mean stress $\sigma_{m} / f_{c 28}$. 


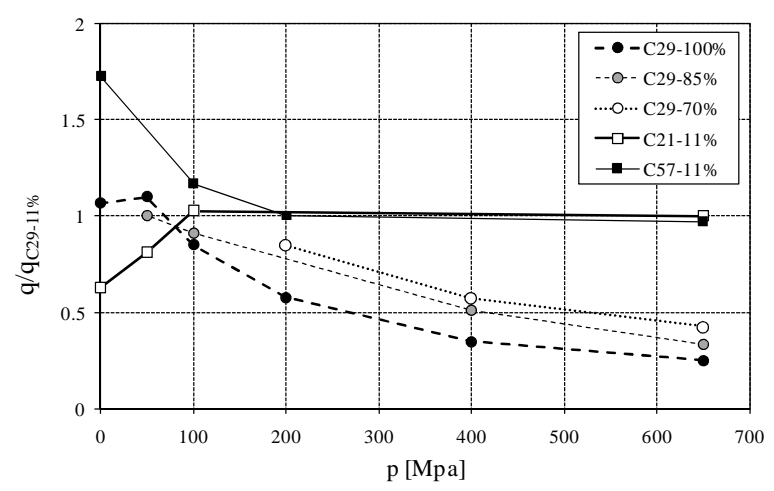

Figure 7. Relative limit states of concretes $\mathrm{C} 21$ ( $\mathrm{Sr}=11 \%), \mathrm{C} 29(\mathrm{Sr}=70 \%, 85 \%$ or $100 \%)$ and $C 57(\mathrm{Sr}=11 \%)$ : Relative deviator $q / q_{29-11 \%} v s$. the confining pressure $p$, where $q_{29-11 \%}$ is the deviatoric stress associated with the limit state of reference concrete C29 for $\mathrm{Sr}=11 \%$.

\section{Conclusions}

This paper has discussed the relevance of analytical models predicting the perforation of reinforced concrete targets.

In case of soft impacts, these formulae have to be developed. In this aim, a first empirical formula is derived from a past report [CEB 1988] and another simple method are proposed. For most tests, experimental and numerical predictions of perforation have shown a good agreement. Ongoing works consist to apply this last method to impacts on steel or composite targets, like tanks - that is not possible using the first approach - . As ballistic limits are proposed, it is also easy to deduce capacities of perforation, i.e. the maximal thickness to be perforated for given impact velocity.

In case of whatever hard or soft impacts, the test results provided in the second part of this article show that under high confinement, the concrete behaves like a non-cohesive granular stacking, on which the cement matrix strength of the fresh concrete no longer exerts any influence. It becomes insensitive with $f_{c 28}$ whereas the saturation ratio exerts a major influence, particularly on both the concrete strength capacity and the volumetric stiffness. According to this new result, the range of application of perforation formulae [1]-[4] presented in the previous section must be considered with caution. 
From an application standpoint, on the one hand, these last results highlight the very small advantages to be gained by increasing the cement concentration in concretes for the purpose of raising their strength capacity to resist to extreme loadings. On the other hand, it seems necessary to evaluate and to take into account the saturation ratio to evaluate precisely the vulnerability under impact of massive concrete infrastructures. In the future, it will be necessary to evaluate the effect of the concrete porosity on the validity of these results. More specifically, do the above conclusions remain valid for very low porosity and/or high performance concretes?

\section{Acknowledgements}

The GIGA press has been installed in the 3SR Laboratory within the scope of a cooperative agreement with the CEA-Gramat. This research has been partially performed with the financial support of the French ministry of defense (DGA). Drs. Buzaud and Pontiroli (CEA-Gramat) are acknowledged for managing tests on slabs. The French Agency (ANR PGCU 2007) is also gratefully acknowledged.

\section{References}

Berriaud C., Dulac J., Sokolovsky A., Labrot R., Gueraud R., Avet-Flancard R., «Local behaviour of reinforced concrete walls under missile impact », Nuclear Engrg and Design, vol. 45, n², 1978, p. 457-469.

Berriaud C., Dulac J., Perrot J., Avet-Flancard R., «Impact on concrete: Synthesis of French Studies », Proc. 7th SMiRT, Chicago, USA, 1983, paper n ${ }^{\circ} 8 / 2$.

Bignon P.G., Riera J.D., « Verification of methods of analysis for soft missile Impact problems », Nuclear Engrg and Design, vol. 60, n³, 1980, p. 311-326.

Buzaud E., Cazaubon C., Chauvel D., « Assessment of empirical formulae for local response of concrete structures to hard projectile impact », Proc. CONSEC 07, Tours, France, 2007, p. 1365-1372.

CEB, «Concrete structures under impact and impulsive loading », Comité EuroInternational du Béton, Bulletin d'Information, ${ }^{\circ} 87$, 1988, Lausanne, Switzerland.

Dupray F, Malécot Y, Daudeville L, Buzaud E, «A mesoscopic model for the behaviour of concrete under high confinement », International J. for Numerical and Analytical Methods in Geomechanics, vol. 33, n¹1, 2009, p. 1407-1423.

Dupray F, Malécot Y, Daudeville L, «Experimental behaviour of high-performance concrete in confined tension », Materials and Structures, vol. 43, n ${ }^{\circ}$, 2010, p. 699-707

Eibl J., «Soft and hard Impact. Concrete for hazard protection», Concrete Society, Edinburgh, UK, 1987, p. 175-186. 
Gabet T, Vu X.H., Malécot Y, Daudeville L., «A new experimental technique for the analysis of concrete under high triaxial loading », J. de Physique IV, vol. 134, 2006, p. 635-644.

Gabet T, Malécot Y, Daudeville L., «Triaxial behavior of concrete under high stresses: Influence of the loading path on compaction and limit states », Cement and Concrete Research, vol. 38, n³, 2008, p. 403-412.

Gran J. K., Frew D. J., «In-target radial stress measurements from penetration experiments into concrete by ogive-nose steel projectiles », International J. of Impact Engrg, vol. 19, n8, 1997, p. 715-726.

IRIS, «Benchmark on improving robustness assessment methodologies for structures impacted by missiles », NEA/IAGE Workshop, 13-15 December 2010. NEA Headquarters, France.

Johnson G. R. and Cook W. H., «Fracture characteristics of three metals subjected to various strains, strain rates, temperatures and pressures », Engrg Fracture Mechanics, vol. 21, ${ }^{\circ} 1,1985$, p. 31-48.

Jonas W., Meschkat R., Riech H., Rüdiger E., «Experimental investigations to determine the kinetic ultimate bearing capacity of reinforced concrete slabs subject to deformable missiles », Proc. 5th SMiRT, Berlin, Germany, 1979, J8/3.

Jones N., « Structural impact », Cambridge University Press, 1989.

Li Q.M., Reid S.R., Wen H.M., Telford A.R., « Local impact effects of hard missiles on concrete targets », International J. of Impact Engrg, vol. 32, n 1-4, 2005, p. 224-284.

Malécot Y, Daudeville L, Dupray F, Poinard C, Buzaud E, « Strength and damage of concrete under high triaxial loading », European J. of Environmental and Civil Engrg, vol. 14, n6-7, 2010, p. 777-803.

Mébarki A., Nguyen Q.B., Mercier F., Ami Saada R., Reimeringer M. «Reliability analysis of metallic targets under metallic rods impact: towards a simplified probabilistic approach », J. of Loss Prevention in the Process Industries, vol. 21, n5, 2008, p. 518-527.

Moore J. et al., «IRIS 2010 International Benchmark, Improving robustness assessment methodologies for structures impacted by missiles, workshop proceedings », Working Group of components and structures, report of team ENSI / B\&H, IRSN editor, 2010.

Nachtsheim W., Stangenberg F., «Interpretation of results of Meppen slab tests Comparison with parametric investigations », Nuclear Engrg and Design, vol. $75, \mathrm{n}^{\circ} 2,1982$, p. 283-290.

Poinard C, Malécot Y, Daudeville L, «Damage of concrete in a very high stress state: Experimental investigation », Materials and Structures, vol. 43, $\mathrm{n}^{\circ} 1-2$, 2010, p. 15-29. 
Pontiroli C., Rouquand A., Mazars J., « Predicting concrete behaviour from quasistatic loading to hypervelocity impact. An overview of the PRM Model», European J. of Environmental and Civil Engrg, vol 14, n6-7, 2010, p.703-727.

Pontiroli C., Rouquand A., «Soft projectile impacts analysis on thin reinforced concrete slabs: tests, modeling, simulations », European J. of Environmental and Civil Engrg, 2011 (to appear).

Riera J.D., « On the stress analysis of structures subjected to aircraft impact forces », Nuclear Engrg and Design, vol. 8, n 4, 1968, p. 415-426.

Vu X.H., Malécot Y, Daudeville L, Buzaud E., «Experimental analysis of concrete behavior under high confinement: Effect of the saturation ratio », International $J$. of Solids and Structures, vol. 46, n5, 2009a, p. 1105-1120.

Vu X.H., Malécot Y, Daudeville L., «Strain measurements on porous concrete samples for triaxial compression and extension tests under very high confinement », J. of Strain Analysis for Engrg Design, vol. 44, n8, 2009b, p. 633-657.

Vu X.H., Malécot Y, Daudeville L, Buzaud E, «Effect of the water/cement ratio on concrete behavior under extreme loading », International J. for Numerical and Analytical Methods in Geomechanics, vol. 33, n¹7, 2009c, p. 1867-1888. 